\title{
BEHAVIOURAL CONSEQUENCES OF THE PERFORMANCE MEASUREMENT SYSTEM (PMS) IN A DECISION-FACILITATING ROLE - A REVIEW
}

\author{
Zarinah Abdul Rasit ${ }^{1}$ and Kamisah Ismail
}

\begin{abstract}
The shortcomings of traditional PMS have led to the use of a more comprehensive PMS, which is widely used for decision-facilitating as well as decision-influencing purposes. Performance measurements for decision-facilitating or a cognitive role refer to the use of PMS to provide information to guide managers in decision-making whilst performance measurements used for a decision-influencing or motivation role refers to their use in the performance evaluation functions. Considerable prior PMS research identified the inconsistent findings in the relationship between PMS and organisational performance, thus, promoting the subsequent PMS related research to further explore the behavioural implications of PMS. This paper discusses the review of the literature examining the behavioural consequences of PMS. This review of the literature identified the conflicting findings from prior research and determined that research examining the informational characteristics of PMS on individual behaviour is still lacking.
\end{abstract}

Keywords: Performance measurement system, decision-facilitating role, MAS

\section{Introduction}

The changes in technology, shortened product lifecycle and innovation in production processes have significant implications concerning the use of management accounting systems (MAS), in particular, the performance measurement system (PMS). Traditional or short-term financial measures are no longer adequate to provide information that is essential for managers' decisionmaking. Such a situation concerning the traditional accounting system has

\footnotetext{
$1 \quad$ Corresponding author: Dr Zarinah Abdul Rasit is a Senior Lecturer at Faculty of Accountancy, UiTM, Shah Alam, email:zarinahar@gmail.com. Dr Kamisah Ismail is a Senior Lecturer at the Faculty of Business and Accountancy, University of Malaya.
} 
resulted in the use of a broader set of performance measures. Kaplan and Norton (1992) introduced the Balanced Scorecard (BSC) to account for the limitation of the traditional accounting system. BSC is characterised by its diverse and comprehensive system, which provides a better system for evaluating managerial performance. According to Hall (2008), PMS techniques, such as BSC (Kaplan \& Norton, 1996), Tableau de board (Epstein \& Manzoni, 1998) and performance hierarchies (Lynch \& Cross, 1991), provide managers with a broad set of measures covering the important areas of the firm. In addition, the Strategic Performance Measurement System (SPMS) is also used by organisations as a performance measurement tool. Specifically, SPMS helps the organisation to provide useful information to employees to facilitate behaviour in achieving organisational success (Kaplan \& Norton, 2001).

Based on the review of the literature, in prior research, the terms BSC, SPMS and CPMS were used interchangeably. BSC is defined as a set of measures that gives top managers a fast but comprehensive view of the business. The system includes the financial and operational measures for customers' satisfaction, internal processes, and the organisation's innovation and improvement activities - operational measures that are the drivers of future financial performance (Kaplan \& Norton, 1996, p. 71). BSC is considered to be a comprehensive control system and is also referred to as SPMS (Ittner et al., 2003; Ullrich \& Tuttle, 2004). BSC is a widely known SPMS (White, 2008) and is considered to be a comprehensive PMS (Malina \& Selto, 2001). According to Burney and Matherly (2007), SPMS is different from traditional PMS, as traditional PMS emphasises the financial measures of performance whereas SPMS combines both financial and non-financial measures that are chosen through a filtering process to represent organisational strategy. Hence, SPMS permits an organisation to communicate information regarding its long-term strategy, the relations among the various organisational strategic objectives, and the link between strategic goals and the employees' actions (Burney \& Matherly, 2007; Ittner \& Larcker, 1998).

SPMS is still the subject of extensive research and analysis to determine its benefits as well as its limitations (Micheli \& Manzoni, 2009). Prior research in the area of PMS is divided into two (2) streams - the first stream of research examines the relationship between PMS and organisational performance (Hoque, 2004; Hoque \& James, 2000; Ittner et al., 2003; Van der Stede et al., 2006). Furthermore, past research examining the link between SPMS and organisational performance indicate ambiguous findings (Chenhall, 2005; Micheli \& Manzoni, 2009). The second stream of PMS research contends that, to some extent, the major purpose of PMS would influence the behaviour of individuals whose actions have significant influence on organisational performance (de Haas \& Kleingeld, 1999; Otley, 1999). Management accounting information, particularly performance measures, provides two main purposes: decision-influencing role and decision-facilitating role (Grafton et al., 2010; Kren, 1992; Sprinkle, 2003; van Veen-Dirks, 2010). The decision-influencing role relates to the use of 
managerial accounting information to alleviate organisational control problems for the purpose of motivating and controlling the managers and employees. Alternatively, the decision-facilitating role refers to the use of management accounting information to resolve pre-decision uncertainty.

Prior research indicates that even though CPMS is useful in providing information, it may lead to negative effects (Banker et al., 2004; Cheng et al., 2007; Lipe \& Salterio, 2000; Moers, 2005). Research on the behavioural aspect of SPMS implementation found that managers' cognitive limitations may prevent organisations to benefit fully from using the system, and differences in cognitive limitation may lead to differences in using PMS. The use of SPMS (BSC) can be problematic, as managers tend to ignore certain information from PMS (Banker et al., 2004; Lipe \& Salterio, 2000; Moers, 2005). This is because an individual manager is unable to process a lot of information. Thus, using comprehensive or SPMS may affect decision-making and may lead to negative implications towards managerial behaviour. This implies a more complex and indirect relationship between SPMS and managerial performance. Therefore, there is a need to close this gap by reviewing prior PMS literature to further explore how PMS may influence behaviour; primarily, individual actions were claimed to make considerable contributions towards organisational performance (de Haas \& Kleingeld, 1999; Otley, 1999). Thus, the objective of this paper is to explore the literature and examine the implications of PMS on individual behaviour, in particular, the PMS cognitive role or decision-facilitating role.

Understanding the behavioural implications of PMS is essential to ensure the effective use of the system in an organisation. This paper is organised as follows. The next section describes the relevant literature and examines the relationship between PMS and organisational performance. Then, the following section discusses the literature in respect of the behavioural implications of PMS, the decision-facilitating role of PMS, and, finally, the last section presents the conclusion.

\section{PMS and Organisational Performance}

The extant PMS-related research indicates ambiguous findings concerning the relationship between PMS and organisational performance (Chenhall, 2005; Davis \& Albright, 2004; Hoque \& James, 2000; Ittner et al., 2003; Said et al., 2003; Van der Stede et al., 2006). Hoque and James (2000) examine the association between BSC usage and organisational performance using the contingency framework. BSC was measured using the four generic performance measure perspectives customer, financial, learning and growth, and internal aspects. Based on a survey conducted on 66 Australian manufacturing firms, the results show a significant positive association between performance and the greater usage of BSC. Using archival data, Said et al. (2003) examine the implications of the non-financial performance measures included in compensation contracts on current and future 
performance. The archival data covering the period from 1993 to 1998 was used in the study to examine the difference. The findings indicate that firms that employ a combination of financial and non-financial performance measures have significantly higher mean levels of return on assets (ROA) and higher levels of market returns. Overall, the results indicate that the association between the use of non-financial measures and firm's performance is dependent on the match between the firm's use of non-financial measures and competitive characteristics.

According to Davis and Albright (2004), BSC can be used not only as a PMS but also as a medium of communication to the business unit about the longterm strategic initiatives for achieving long-term performance. Their research investigates the impact of BSC on a banking institution's financial performance. The findings show that bank branches that implement BSC demonstrate superior financial performance compared to bank branches that do not implement BSC. Van der Stede et al. (2006) examine the relationship between a quality-based manufacturing strategy and the use of the different types of performance measures - objective and subjective non-financial measures. From a survey on 128 European and US manufacturing firms, the results show that, regardless of strategy, performance measurement diversity, or extensive PMS (objective or subjective non-financial measures) benefits performance.

Ittner and Larcker (2003) conducted field research in more than 60 manufacturing and service companies and supplemented it with surveys on 297 senior executives. The findings indicate that companies that efficiently use their PMS and demonstrate a causal link between their performance measures would show higher performance (ROA and ROE). Companies would perform better if they were able to identify which non-financial factors have the most powerful effects on long-term performance. However, some of the research examining the effect of PMS on organisational performance found ambiguous findings. Ittner, Larcker and Randall (2003) examine the relation between two approaches of strategic performance measurement (greater measurement diversity, and improved alignment with firm strategy and value drivers), and measurement system satisfaction and economic performance. Based on a sample of 140 US services firms from a single industry, Ittner et al. (2003) find that although the measurement diversity approach has the strongest association with stock market performance, there is no association with economic performance.

Using the contingency framework, Hyvonen (2007) provides empirical evidence showing the disadvantages of using the contemporary performance measure. The results show that the PMS and advance manufacturing technology (AMT) do not help firms with a customer focused strategy to improve performance. However, the research identifies the financial measures to help firms with a customer-focused strategy to improve performance. Chenhall (2003) claims that there is an implied connection between Management Control System (MCS) and organisational outcomes. He anticipates that there is a broad leap linking MCS and organisational performance, which indicates the need to focus 
on the implications of the MCS on the individual manager's behaviour to improve organisational performance. MCS can offer satisfaction to individuals if managers perceive the system as being useful in providing improved information relating to their task. As a result, an individual will manage to make better decisions in achieving organisational goals. However, there is a lack of compelling evidence to support the link between the usefulness of MCS and improved job satisfaction or organisational performance. Presently, due to the greater emphasis of human element issues relating to PMS, the current research has shifted to examine the behavioural implications of SPMS (de Waal, 2002). According to Schiff and Hoffman (1996), a large number of measures may actually reduce the performance of managers. This is due to the extensive measures used that may exceed the processing capabilities of managers when making judgments. Thus, this would direct the manager to fail to set a clear direction, which would create uncertainty and ambiguity.

\section{Behavioural Implication of PMS}

Prior PMS-related research on behavioural consequences of PMS design focused on the PMS role, as either decision-facilitating or decision-influencing, and applied a range of theories - cognitive psychology, cognitive motivational theory (Hall, 2008), role theory (Burney \& Widener, 2007), goal setting theory (Cheng et al., 2007; Webb, 2004), organisational fairness theory, self-interest theory (Lau \& Sholihin, 2005), economic theory and agency theory (Burney et al., 2009), and attribution theory (Hartmann \& Slapnicar, 2009; Schiff \& Hoffman, 1996).

\subsection{PMS as a Decision-facilitating Role}

For research examining the behavioural implication of PMS as a decisionfacilitating role, empirical evidence indicates that there is a positive implication of PMS on managerial behaviour (Burney \& Widener, 2007; Hall, 2008; Webb, 2004). Although empirical research in this area is still lacking, the research somehow supports prior research that suggests a better fit of an indirect relationship between a control system and performance (Shields et al., 2000). Shields et al. (2000) test the effect of two models of the control systems - direct model and indirect model of performance. The components of the control system examined includes standard-based incentives, standard tightness and subordinate participation in a standard setting. Using structural-equation modelling to test the hypothesis, research indicates that the indirect model shows a better fit to the data in contrast to the direct model. The results indicate that there is an intervening effect of job-related stress between the components of the control system and job performance. The link between the components of the control system and job performance is identified to be stronger for the indirect model compared to the direct model. 
The findings imply a complex link between the control system and performance, which is influenced by certain types of behaviour. The results also suggest that there is a better fit for a model showing an indirect relation between the control system and performance. Prior research examining the behavioural implication of PMS supports Shield's model, in that there is an indirect effect between PMS (a control system) and performance. Prior research in this area identifies that the relationship between PMS and individual performance is mediated and influenced by factors, such as role ambiguity and job relevant information (Burney \& Widener, 2007), procedural fairness and organisation commitment (Lau \& Moser, 2008), psychological empowerment and role clarity (Hall, 2008), trust and fairness (Lau \& Sholihin, 2005), justice perception (Burney et al., 2009), creativity and psychological empowerment (Webster, 2006), and goal specificity (Sholihin et al., 2010). The findings of the aforementioned research mostly highlight the positive implications of PMS.

Based on an in-depth review of 76 empirical studies, Franco-Santos et al. (2012) developed a conceptual framework that explains how the system may positively influence individual behaviour. The model shows the consequences of contemporary PMS and the theories underlying the research. As depicted in Figure 1, their framework suggests that the consequences of CPM can be classified into people's behaviour, organisational capabilities and performance consequences. The framework implies that CPM systems significantly affect people's behaviour. Particularly, the consequences of people's behaviour are comprised of people's specific actions and underlying cognitive mechanisms, such as motivation, perceptions and cooperation. The extent to which the system positively influences people's behaviour is directly associated with how the system is designed, developed, and used, and fits in the context it is operated (Franco-Santos et al., 2012).

The conceptual framework developed by Franco-Santos et al. (2012) is as shown below:

Figure 1: Conceptual Framework developed by Franco Santos et al. (2012)

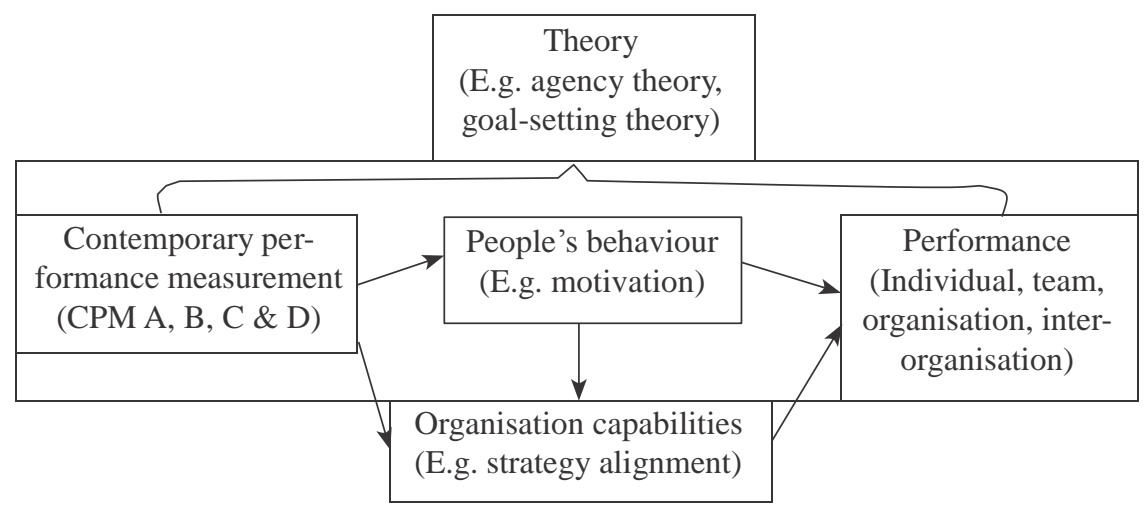


Burney and Widener (2007) find that PMS that is strategically linked has a positive implication on managerial performance. The results were based on data from over 700 respondents, indicating that SPMS is positively associated with managerial performance. The findings also indicate that the relationship is indirect. Particularly, research provides evidence that the link between SPMS and performance is mediated by job-relevant information and role stressors. SPMS can enhance the levels of job-relevant information (JRI) and alleviate the levels of role stressors, which are then associated with the higher levels of managerial performance. SPMS contains informative content, as managers tend to search for JRI when using SPMS, which leads to less role ambiguity and role conflict. In other words, SPMS will enhance the managers' JRI and reduce role ambiguity and role conflict. SPMS closes the gap between the information required and information available to perform duties.

Burney and Widener (2007) also identify that the link between SPMS and JRI, RA and RC is moderated by the evaluative process, complexity, and managerial experience. Role ambiguity is reduced as managers have a clear expectation to perform duties, which, in turn, cause an improvement in managerial behaviour through strategic planning and decision-making. The implication of SPMS relates to the design and use of the system, which is moderated by evaluation, complexity and experience. The findings of the research seem to suggest that the strongest relation with JRI is associated with the low or high levels of managers' experience. Further, the strongest relation between SPMS and RA is linked to the evaluation of the low or high levels of managerial experience. When complexity is low, the link between SPMS and role conflict is strong. Hence, in order to ensure that an organisation will achieve high performance, certain factors, such as evaluation, complexity and experience, should be taken into consideration.

Similar to the research by Burney and Widener (2007), Webb (2004) also examines the behavioural consequences of SPMS. SPMS is defined as a set of causally linked non-financial and financial objectives, performance measures, and goals designed to align the actions of managers with an organisation's strategy (Webb, 2004). She argues that SPMS has a unique feature in which the system has its cause-effect structure. In the research, this unique feature of SPMS is determined to have an effect on goal commitment. Goal commitment is an important antecedent to managerial performance. The results show that if an individual is inclined to commit themselves to achieve a difficult goal or multiple objectives set in the SPMS, these will consequently lead to improvement in the overall performance. The research identified two features central to the SPMS approach, which are predicted to affect goal commitment; firstly, the strength of the cause-effect links among the non-financial and financial performance measures and contained in an SPMS, and, secondly, the managers' belief in their ability to achieve the non-financial goals of SPMS. 
Past researchers examined the effect of CPMS on performance. CPMS was found to produce a positive effect on performance (Hall, 2008; Scott \& Tiessen, 1999). Based on research on cognitive psychology, with regard to the system informational effects, SPMS was identified to be able to help managers frame mental representations of the business. Based on psychological theories, Hall (2008) examines the relationship between CPMS and managerial performance. The study determines that the effect of CPMS on managerial performance is indirect through the mediating variables of role clarity and psychological empowerment. Data collected for the study were from a survey of 83 strategic business unit managers. This study suggests that the role of cognitive and motivational mechanisms may provide an explanation in the relation between the MAS and managerial performance (Collins, 1982). The results suggest that the PMS provides managers with information that can influence the cognition and motivation of managers, which may lead to enhanced managerial performance. CPMS will provide managers with relevant information that will help them to be clear about their role. The PMS can also enhance the empowerment of managers, which, in turn, improves their performance.

Prior research also examined the implications of the use and innovation of PMS. Webster (2006) examines the influence of the use of PMS (interactive use of PMS) in enhancing performance and innovation. Data were collected using a survey on a sample of middle-level managers of large Australian manufacturing organisations. The nature of the relationship between the variables was examined using Partial Least Squares (PLS) analysis. The findings of the research suggest that there was an indirect significant relationship between the interactive use of PMS and performance. Despite the influence being indirect, the findings provide support for the influence of PMS use and individual outcome. The study identified a few key variables to mediate the relationship. Psychological empowerment was found to be instrumental in the relation between the interactive use of PMS and individual performance and between the interactive use of PMS and creativity. Additionally, evidence also shows that psychological empowerment mediates the associations between the interactive use of PMS and the individual outcomes of creativity and performance. These findings suggest that PMS use also has behavioural implications. The use of PMS can enhance the individual's psychological empowerment and lead to higher creativity and performance.

Burney and Swanson (2010) focus on the effect of BSC on the behaviour of managers. Particularly, their research investigates the implications of the two major characteristics of BSC (strategy link and the perspective framework) on the job satisfaction of managers. Data were collected using a questionnaire survey method and sample consisting of 763 accounting managers who were also members of the Institute of Management Accountants in BSC firms. The results demonstrate a strong positive relation between the perception of the respondents concerning the strength of the link between the performance measures, and organisational strategy and job satisfaction. This findings also imply that PMS 
has a strong connection with strategy (first characteristic) and may reduce the ambiguity of managers as they are better informed about organisational-desired actions. Additionally, the evidence suggests that greater emphasis on using leading indicators (second characteristic) for decision-making is associated with greater job satisfaction.

Other research provides empirical evidence that indicates the negative implications of using PMS. Rinsum and Verbeeten (2010) also add to the empirical evidence, showing the negative implications of PMS. However, their research is in the context of public sector organisations. Their research predicts that subjectivity in the PMS may have negative implications on a manager's motivation. Subjective PMS has a negative effect or may reduce mission clarity and the subordinate's trust. Based on a survey among 94 public sector managers in the Netherlands, their research finds support implying that subjectivity in PMS does not provide better informational feedback. The results support their hypotheses and show that subjectivity in PMS reduces the mission clarity and trust of managers, which results in a decrease in motivation.

Similarly, the empirical evidence by Cheng et al. (2007) provides further evidence concerning the negative behavioural consequences of PMS. Various prior research examines those managers who make performance evaluation judgements (Lipe \& Salterio, 2000; Moers, 2005). Cheng et al. (2007) examine the implications of contemporary PMS on those managers who are being evaluated. Their research suggests that the use of multiple performance measures may have undesirable effects due to the limited cognitive ability of managers to cope with incompatible demands from the inclusion of multiple goals. Based on the survey data from employees in a telecommunications company, the results demonstrate that in the use of contemporary PMS, perceived goal difficulty increases perceived goal conflict. Additionally, it is revealed that perceived goal difficulty has a negative and indirect effect on task performance through perceived goal conflict. PMS provides information, which may enhance the understanding of individual managers regarding work expectation, which may be influenced by the individual's perception of goal difficulty and goal conflict on their performance.

\section{Conclusion}

The review of prior literature indicates that research that examines the behavioural consequences of PMS as a decision-facilitating role is still lacking. Limited research has examined how PMS would influence the behaviour of managers (Burney \& Widener, 2007; Ittner \& Larcker, 1998; Webb, 2004). However, generally, research examining the informational characteristics of PMS provides evidence that there is a positive implication of PMS on individual behaviour. This line of research provides evidence that PMS has an important influence on individual behaviour, which may influence organisational performance. It is generally recognised by the organisational theory that individual actions may 
largely contribute to the organisation's long-term success (de Haas \& Kleingeld, 1999; Otley, 1999).

However, some research indicates ambiguous findings. The contemporary PMS is also identified and may result in detrimental effects due to the limited cognitive ability of managers to cope with incompatible demands from the inclusion of multiple goals (Cheng et al., 2007). It was also found that the use of PMS might not be able to provide better informational feedback. In addition, it may lead to a negative effect due to reduced mission clarity and subordinate trust that may result in reduced motivation (Van Rinsum \& Verbeeten, 2010). This review of the literature also provides evidence and support concerning how the MAS information, particularly PMS, may influence an individual's behaviour. Besides the decision-facilitating role, a future review of the literature should also identify how the decision-influencing role of PMS may influence an individual's behaviour.

\section{References}

Banker, R. D., Chang, H., \& Pizzini, M. J. (2004). The Balanced Scorecard: Judgmental Effects of Performance Measures Linked to Strategy. Accounting Review, 79(1), 1-23.

Burney, L., Henle, C. A., \& Widener, S. K. (2009). A path model examining the relations among strategic performance measurement system characteristics, organizational justice, and extra- and in-role performance. Accounting, Organizations and Society, 34(3-4), 305-321.

Burney, L., \& Matherly, M. (2007). Examining Performance Measurement from an Integrated Perspective. Journal of Information Systems, 21(2), 49.

Burney, L., \& Swanson, N. (2010). The Relationship Between Balanced Scorecard Characteristics and Managers' Job Satisfaction*. Journal of Managerial Issues, 22(2), 166.

Burney, L., \& Widener, S. (2007). Strategic Performance Measurement Systems, Job-Relevant Information, and Managerial Behavioral Responses--Role Stress and Performance. Behavioral Research in Accounting, 19, 43-69.

Cheng, M. M., Luckett, P. F., \& Mahama, H. (2007). Effect of perceived conflict among multiple performance goals and goal difficulty on task performance. Accounting \& Finance, 47(2), 221-242.

Chenhall, R. H. (2003). Management control systems design within its organizational context: findings from contingency-based research and directions for the future. Accounting, Organizations and Society, 28(2-3), 127-168.

Chenhall, R. H. (2005). Integrative strategic performance measurement systems, strategic alignment of manufacturing, learning and strategic outcomes: an exploratory study. Accounting, Organizations and Society, 30(5), 395-422. 
Collins, F. (1982). Managerial accounting systems and organizational control: A role perspective. Accounting, Organizations and Society, 7(2), 107-122.

Davis, S., \& Albright, T. (2004). An investigation of the effect of Balanced Scorecard implementation on financial performance. Management Accounting Research, 15(2), 135-153.

de Haas, M., \& Kleingeld, A. (1999). Multilevel design of performance measurement systems: enhancing strategic dialogue throughout the organization. Management Accounting Research, 10(3), 233-261.

de Waal, A. A. (2002). The role of behavioral factors in the successful implementation and use of performance management systems. Performance Measurement and Management: Research and Action, Centre for Business Performance, Cranfield School of Management, Cranfield, 157-164.

Epstein, M., \& Manzoni, J.-F. (1998). Implementing corporate strategy:: From Tableaux de Bord to balanced scorecards. European Management Journal, 16(2), 190-203.

Franco-Santos, M., Lucianetti, L., \& Bourne, M. (2012). Contemporary performance measurement systems: A review of their consequences and a framework for research. Management Accounting Research, 23(2), 79-119.

Grafton, J., Lillis, A. M., \& Widener, S. K. (2010). The role of performance measurement and evaluation in building organizational capabilities and performance. Accounting, Organizations and Society, 35(7), 689-706.

Hall, M. (2008). The effect of comprehensive performance measurement systems on role clarity, psychological empowerment and managerial performance. Accounting, Organizations and Society, 33(2-3), 141-163.

Hartmann, F., \& Slapnicar, S. (2009). How formal performance evaluation affects trust between superior and subordinate managers. Accounting, Organizations and Society, 34(6-7), 722-737.

Hoque, Z. (2004). A contingency model of the association between strategy, environmental uncertainty and performance measurement: impact on organizational performance. International Business Review, 13(4), 485-502.

Hoque, Z., \& James, W. (2000). Linking Balanced Scorecard Measures to Size and Market Factors: Impact on Organizational Performance. (cover story). Journal of Management Accounting Research, 12, 1-17.

Hyvonen, J. (2007). Strategy, performance measurement techniques and information technology of the firm and their links to organisational performance. Management Accounting Research, 18, 343-366.

Ittner, C. D., \& Larcker, D. F. (1998). Innovations in performance measurement: Trends and research implications. Journal of Management Accounting Research, 10, 205.

Ittner, C. D., \& Larcker, D. F. (2003). Coming Up Short on Nonfinancial Performance Measurement. Harvard Business Review, 81(11), 88-95. 
Ittner, C. D., Larcker, D. F., \& Randall, T. (2003). Performance implications of strategic performance measurement in financial services firms. Accounting, Organizations and Society, 28(7-8), 715-741.

Kaplan, R. S., \& Norton, D. P. (1992). The Balanced Scorecard--Measures That Drive Performance. Harvard Business Review, 70(1), 71-79.

Kaplan, R. S., \& Norton, D. P. (1996). Using the balanced scorecard as a strategic management system. Harvard Business Review, 74(1), 75-85.

Kaplan, R. S., \& Norton, D. P. (2001). The strategy-focused organization. Strategy \& Leadership, 29(3), 41.

Kren, L. (1992). Budgetary Participation and Managerial Performance: The Impact of Information and Environmental Volatility. Accounting Review, 67(3), 511-526.

Lau, C. M., \& Moser, A. (2008). Behavioral Effects of Nonfinancial Performance Measures: The Role of Procedural Fairness. Behavioral Research in Accounting, 20(2), 55-71.

Lau, C. M., \& Sholihin, M. (2005). Financial and nonfinancial performance measures: How do they affect job satisfaction? The British Accounting Review, 37(4), 389-413.

Lipe, M. G., \& Salterio, S. E. (2000). The Balanced Scorecard: Judgmental Effects of Common and Unique Performance Measures. Accounting Review, 75(3), 283.

Lynch, R. L., \& Cross, K. F. (1991). Measure up! : yardsticks for continuous improvement. Cambridge, Mass., USA: Blackwell Business.

Malina, M., A. , \& Selto, F., H. . (2001). Communicating and controlling strategy: An empirical study of the effectiveness of the balanced scorecard. Journal of Management Accounting Research, 13, 47.

Micheli, P., \& Manzoni, J.-F. (2009). Strategic Performance Measurement: Benefits, Limitations and Paradoxes. Long Range Planning, In Press, Corrected Proof.

Moers, F. (2005). Discretion and bias in performance evaluation: the impact of diversity and subjectivity. Accounting, Organizations and Society, 30(1), 67-80.

Otley, D. (1999). Performance management: a framework for management control systems research. Management Accounting Research, 10(4), 363-382.

Said, A. A., HassabElnaby, H. R., \& Wier, B. (2003). An Empirical Investigation of the Performance Consequences of Nonfinancial Measures. Journal of Management Accounting Research, 15, 193-223.

Schiff, A. D., \& Hoffman, R. (1996). An Exploration of the Use of Financial and Nonfinancial Measures of Performance by Executives in a Service Organization. Behavioral Research in Accounting, 8, 134-153.

Scott, T. W., \& Tiessen, P. (1999). Performance measurement and managerial teams. Accounting, Organizations and Society, 24(3), 263-285. 
Shields, M. D., Deng, F. J., \& Kato, Y. (2000). The design and effects of control systems: tests of direct- and indirect-effects models. Accounting, Organizations and Society, 25(2), 185-202.

Sholihin, M., Pike, R., \& Mangena, M. (2010). Reliance on multiple performance measures and manager performance. Journal of Applied Accounting Research, 11(1), 24-42.

Sprinkle, G. B. (2003). Perspectives on experimental research in managerial accounting. Accounting, Organizations and Society, 28(2-3), 287-318.

Ullrich, M. J., \& Tuttle, B. M. (2004). The Effects of Comprehensive Information Reporting Systems and Economic Incentives on Managers'Time-Planning Decisions. Behavioral Research in Accounting, 16, 89-105.

Van der Stede, W. A., Chow, C. W., \& Lin, T. W. (2006). Strategy, Choice of Performance Measures, and Performance. Behavioral Research in Accounting, 18, 185-205.

Van Rinsum, M., \& Verbeeten, F. (2010). The Impact of Subjectivity in Performance Evaluation Practices on Public Sector Manager s Motivation. SSRN eLibrary.

van Veen-Dirks, P. (2010). Different uses of performance measures: The evaluation versus reward of production managers. Accounting, Organizations and Society, 35(2), 141-164.

Webb, R. A. (2004). Managers' Commitment to the Goals Contained in a Strategic Performance Measurement System*. Contemporary Accounting Research, 21(4), 925.

Webster, C. (2006). An empirical analysis of the relationships between the interactive use

of performance measurement systems, creativity and performance: the intervening role of psychological empowerment. http://www.afaanz.org/research/ AFAANZ\%2006186.pdf., 29th Annual Congress of the European Accounting ..., 2006 - afaanz.org

White, L. (2008). The Use of Performance Measures and Their Outcomes. Journal of American Academy of Business, Cambridge, 13(1), 133. 